\title{
Effect of brown adipose tissue/cells on the growth of mouse hepatocellular carcinoma in vitro and in vivo
}

\author{
DONG LIU, YI LI, YUE SHANG, WENDIE WANG and SHU-ZHEN CHEN \\ Institute of Medicinal Biotechnology, Chinese Academy of Medical Sciences and Peking Union \\ Medical College, Beijing 100050, P.R. China
}

Received February 2, 2018; Accepted December 21, 2018

DOI: $10.3892 /$ ol.2019.9977

\begin{abstract}
Activation of brown adipose tissue (BAT) is an effective strategy for treating obesity. Hepatocellular carcinoma (HCC) is a life-threatening hepatic malignancy with a high mortality rate. Considering that obesity is a risk factor for $\mathrm{HCC}$, the aim of the present study was to investigate the association between HCC and BAT. Using a mouse model, H22 transplantation led to an increase in liver weight, a decrease in the weight of BAT and white adipose tissue, and an increase in the serum level of triacylglycerol (TG). In the in vivo BAT excision model, the removal of BAT led to increased growth of H22 tumors, which was accompanied by a more marked increase in liver weight and in the serum level of TG. The in vitro and in vivo intervention models with primary brown adipose cells (BACs) indicated that primary BACs can directly decrease the viability of $\mathrm{H} 22$ cells and the growth of tumors. In conclusion, BAT is a protective organ or tissue against $\mathrm{HCC}$, and BACs may be a potential therapeutic tool for the treatment of HCC.
\end{abstract}

\section{Introduction}

Adipose tissue serves a vital role in regulating metabolism. Two different types of adipose tissue, white adipose tissue (WAT) and brown adipose tissue (BAT), have been recognized in mammals. Although WAT has attracted considerable attention in various research fields, the progress of investigating BAT remains slow.

In the last decade, it has been demonstrated that BAT is a therapeutic target of obesity and other associated metabolic diseases. BAT was first described in 1551 by K. Gessner in the interscapular region of marmots and was validated in the early 20th Century (1). In 2004, BAT was identified in the adult

Correspondence to: Professor Shu-Zhen Chen, Institute of Medicinal Biotechnology, Chinese Academy of Medical Sciences and Peking Union Medical College, 1 Tiantan Xili Road, Beijing 100050, P.R. China

E-mail: bjcsz@imb.pumc.edu.cn

Key words: brown adipose tissues, hepatocellular carcinoma, brown adipose tissue excision, $\mathrm{H} 22$ cell viability human body by fluorodeoxyglucose-positron emission tomography (2,3). Ultimately, in 2009, the presence of a metabolically active form of BAT in the adult human body was identified in three independent studies (4-6). Of note, in recent years, it has been reported that WAT can acquire similar metabolic functions to those of BAT in a process known as 'browning' (7). Subsequently, the number of studies on the origin, development, activation, function and regulation of BAT has rapidly increased.

Hepatocellular carcinoma (HCC) is one of the most common malignant types of cancer with a high mortality rate. There is a lack of effective strategies for the treatment of HCC in the clinic, particularly for patients with advanced stages of the disease, as surgical resection or transplantation are not suitable owing to serious side effects caused by conventional chemotherapy and radiotherapy. Currently, bio-immunotherapy and targeted therapy are favorable for clinical application because of their relatively low toxicity. However, the self-tolerance immune mechanism of the liver and a lack of candidate target antigens are huge challenges for bio-immunotherapy (8). Furthermore, clinical trials of targeted drugs, with the exception of sorafenib, ended in failure (9-11), which is stagnating the progress of targeted therapy. Therefore, there is an urgent requirement to develop novel HCC treatments with a lower toxicity and a higher efficiency.

To date, owing to a decrease in the incidence of chronic hepatitis infections, the rationale for an increasing number of HCC cases is focused on liver metabolic disorders (12). Metabolic conditions, including obesity, which underlie hepatic metabolic diseases, are becoming emerging risk factors for HCC (13). Considering that the browning of WAT and the activation of BAT have been indicated to be a novel approach for treating obesity (14), it is hypothesized that there are as yet unknown connections between HCC and BAT. BAT may be an inhibitory factor for HCC.

Therefore, to clarify the association between HCC and BAT, a mouse model was used to determine the effect of $\mathrm{H} 22$ cell transplantation on BAT. The in vivo BAT excision model was established to investigate the effect of removing BAT on the growth of $\mathrm{H} 22$ tumors. Furthermore, the in vitro and in vivo intervention models with primary brown adipose cells (BACs) were developed to investigate the interaction of BACs with the H22 cells and tumors, respectively. Furthermore, DNA microarray and signaling pathways [Kyoto Encyclopedia of Genes and Genomes (KEGG)] analyses were used to characterize the 
gene expression profile of the liver. The metabolic alterations in the serum were also investigated by biochemical analysis. A number of previously unreported connections between $\mathrm{BAT} / \mathrm{BACs}$ and $\mathrm{HCC}$ were identified, thus indicating an innovative strategy for HCC treatment.

\section{Materials and methods}

Animals. The animal experiments were conducted according to the Regulations on the Administration of Experimental Animals (2013 revision) issued by the National Scientific and Technological Committee of People's Republic of China. All animal experimental procedures were approved by the Beijing Municipal Science \& Technology Commission (Beijing, China).

A total of 140 female KM mice (18-20 g) at 3-4 weeks old were purchased from HFK Bioscience (Beijing, China), and were fed standard food and water. The mice were housed in cages in a 12 -h light $/ 12$-h dark cycle at $22 \pm 1^{\circ} \mathrm{C}$ and a humidity of $55 \pm 5 \%$. After 2 days of free access to regular food and water, the mice were used for subsequent experiments.

H22 mouse model. H22 ascites, which were frozen and passaged in our laboratory, can be transformed into solid tumors in the armpits of KM mice. First, $1 \mathrm{ml}$ cryopreserved $\mathrm{H} 22$ ascites were thawed and injected into the abdominal cavities of three KM mice. After 2 weeks, the abdominal cavities of KM mice were filled with $\mathrm{H} 22$ ascites. The ascites (dilution, 1:10) were injected into the armpits of 10 female KM mice. These 10 mice were allocated to the tumor $(\mathrm{T})$ group. A further 10 healthy female KM mice were allocated to the control (C) group.

Blood samples were collected from the eyeballs, tumors and livers from 20 mice 10 days later. BATs in the interscapular region and WATs in the inguinal region were dissected and weighed following sacrifice of the mice. At the same time, part of the liver tissues was excised and frozen in liquid nitrogen. At the end of the experiment, the collected blood samples were centrifuged at 3,000 $\mathrm{x}$ g for $5 \mathrm{~min}$ at room temperature, and the serum in the supernatant was stored at $-80^{\circ} \mathrm{C}$ for biochemical analyses.

BAT excision model. A total of $40 \mathrm{KM}$ mice (weight, 18-20 g) were randomly divided into four groups: sham (S), sham and tumor (ST), surgery (O), and surgery and tumor (OT). At day 0 , all mice were anaesthetized by injecting pentobarbital sodium into the abdominal cavities $(50 \mathrm{mg} / \mathrm{kg})$. Incisions $(15-20 \mathrm{~mm})$ were made in the interscapular regions of the mouse skin. For the S and ST groups, the wounds were sutured immediately. For the O and OT groups, BATs in the interscapular region were excised and the wounds were sewed.

At day 4, H22 ascites (dilution, 1:10) were injected into the armpit of mice in the $\mathrm{T}$ and OT groups. At day 14, the blood samples were collected from the eyeballs of 40 mice. Tumors, livers, BATs and WATs in the mice were treated as aforementioned in the $\mathrm{H} 22$ mouse model section.

In vivo primary BAC intervention model. Primary BACs were isolated as described by Marko et al (15). Following sacrifice and sterilization, the BATs in the interscapular region were dissected from the 3 -week-old female mice. The tissues were minced and digested at $37^{\circ} \mathrm{C}$ for $30 \mathrm{~min}$ in an isolation buffer with $1 \mathrm{mg} / \mathrm{ml}$ collagenase $\mathrm{I}, 123 \mathrm{mM}$ $\mathrm{NaCl}, 5 \mathrm{mM} \mathrm{KCl}, 1.3 \mathrm{mM} \mathrm{CaCl}_{2}, 5 \mathrm{mM}$ glucose, $4 \%$ bovine serum albumin (Amresco, Inc., Framingham, MA, USA) and $100 \mathrm{mM}$ 4-(2-hydroxyethyl)-1-piperazine-ethanesulfonic acid ( $\mathrm{pH}$ of 7.4). The digested tissues were passed through a $100-\mu \mathrm{m}$ nylon filter, and the collected BACs were centrifuged at $1,200 \mathrm{x} g$ at room temperature for $5 \mathrm{~min}$. The BACs were resuspended in Dulbecco's modified Eagle's medium (DMEM)/F12 (GE Healthcare, Chicago, IL, USA) containing 20\% FBS (Gibco; Thermo Fisher Scientific, Inc., Waltham, MA, USA), supplemented with penicillin (100 U/ml) and streptomycin $(100 \mu \mathrm{g} / \mathrm{ml})$, in a humidified atmosphere containing $5 \% \mathrm{CO}_{2}$. The medium was changed daily. The identity of BACs was validated using steps as outlined by Gao et al (16) as follows: i) The BACs were induced and differentiated to become mature adipose cells, and ii) the mature BACs were stained with oil red $\mathrm{O}$.

Following stabilization of the primary BACs, $\mathrm{H} 22$ ascites were injected into the armpit of mice at a volume ratio of 1:10 simultaneously adding the different numbers of BACs in the inoculation suspensions. All mice were sacrificed, and the tumors and livers were dissected and weighed 10 days after injection.

In vitro primary $B A C$ intervention model. The in vitro primary BAC intervention model was established by performing a co-culture assay of the primary BACs and $\mathrm{H} 22$ cells using Transwell cell culture inserts (Corning Incorporated, Corning, NY, USA) containing a polycarbonate filter with an $8-\mu \mathrm{m}$ pore size. The $\mathrm{H} 22$ cell line was purchased from the China Center for Type Culture Collection (Wuhan, China). H22 cells were cultured in RPMI-1640 medium (GE Healthcare) supplemented with $10 \%$ FBS and penicillin $(100 \mathrm{U} / \mathrm{ml}) /$ streptomycin $(100 \mu \mathrm{g} / \mathrm{ml})$ at $37^{\circ} \mathrm{C}$ in a humidified atmosphere containing $5 \% \mathrm{CO}_{2}$.

$\mathrm{H} 22$ cell suspensions $\left(2 \times 10^{5} \mathrm{cells} / \mathrm{ml}\right)$ in a volume of $600 \mu \mathrm{l}$ RPMI-1640 complete medium were added to the lower compartment of the chamber. BAC suspensions at different cell densities $\left(7.5 \times 10^{4}, 1.5 \times 10^{5}\right.$ and $3 \times 10^{5}$ cells $\left./ \mathrm{ml}\right)$ in $100 \mu$ DMEM/F12 complete medium were added to the upper compartment of the chamber. After $48 \mathrm{~h}$ of co-culture, the $\mathrm{H} 22$ cells were enumerated using a blood counting chamber. The experiments were performed in triplicate. The complete medium refers to the basal medium (RPMI-1640 or DMEM/F12) supplemented with FBS and penicillin/streptomycin.

Serum biochemistry and histological analyses. Serum cholesterol (CHO), high-density lipoprotein (HDL), low-density lipoprotein (LDL), triacylglycerol (TG) and glucose (GLU) were analyzed using a Hitachi 7100 analyzer (Hitachi, Ltd., Tokyo, Japan) and kits obtained from Zhongsheng Beikong Biotechnology (Beijing, China) (http://www.zhongsheng.com. $\mathrm{cn} /$ ). Formalin-fixed tissues including BAT, WAT and liver were embedded in paraffin, and the sections were stained for $5 \mathrm{~min}$ at room temperature with hematoxylin and eosin using a Hematoxylin-Eosin Staining kit (cat. no., G1120-100, Beijing Solarbio Science \& Technology Co., Ltd., Beijing, China), according to the manufacturer's protocols. The percentage of 
Table I. Effect of H22 cell transplantation in KM mice on body weight, tumor, liver, BAT and WAT.

\begin{tabular}{lccccc}
\hline Group & Body weight, $g$ & Tumor weight, $g$ & Liver weight, $g$ & BAT weight, $g$ & WAT weight, $g$ \\
\hline C & $30.22 \pm 1.74$ & - & $1.805 \pm 0.168$ & $0.277 \pm 0.057$ & $0.161 \pm 0.037$ \\
T & $31.00 \pm 2.40$ & $2.006 \pm 0.299$ & $2.414 \pm 0.219^{\mathrm{a}}$ & $0.244 \pm 0.018$ & $0.134 \pm 0.036$ \\
\hline
\end{tabular}

${ }^{\text {aP }}<0.01$ vs. C. BAT, brown adipose tissue; WAT, white adipose tissue; $\mathrm{C}$, control; $\mathrm{T}$, tumor.

Table II. Effect of H22 cell transplantation in KM mice on the concentration of CHO, HDL, LDL, TG and GLU in serum.

\begin{tabular}{lcccc}
\hline Group & CHO, $\mathrm{mM}$ & HDL, $\mathrm{mM}$ & LDL, mM & TG, mM \\
\hline C & $2.66 \pm 0.36$ & $1.26 \pm 0.19$ & $0.27 \pm 0.08$ & $2.21 \pm 0.41$ \\
T & $2.52 \pm 0.37$ & $1.02 \pm 0.17$ & $0.25 \pm 0.11$ & $3.28 \pm 1.10^{\mathrm{a}}$ \\
\hline
\end{tabular}

${ }^{\mathrm{a} P}<0.01$ vs. C. CHO, cholesterol; HDL, high-density lipoprotein; LDL, low-density lipoprotein; TG, triacylglycerol; GLU, glucose; C, control; $\mathrm{T}$, tumor.

cross-sectional areas for BAT and WAT was quantified, which was determined in three random view fields for each mouse from one group using a Leica QW3 light microscope (Leica Microsystems, Inc., Buffalo Grove, IL, USA).

DNA microarray and KEGG analysis of the livers for the $T$ and OT groups. Five groups, i.e. C, T, S, O and OT, were created using a similar animal modeling process with that aforementioned. The mice in the $\mathrm{C}$ and $\mathrm{T}$ groups were treated with the aforementioned procedures in the $\mathrm{H} 22$ mouse model. The mice in the $\mathrm{S}, \mathrm{O}$ and OT groups was treated with the aforementioned procedures in the BAT excision model. Following sacrifice of the mice, the livers were collected in liquid nitrogen. For the $\mathrm{T}$ and OT groups, three liver tissue samples were selected from three different mice and combined as one sample. The gene expression profiles of the combined sample were analyzed for T vs. OT by DNA microarray and KEGG analysis.

Statistical analysis. The data and results were calculated with Excel 2016 (Microsoft Corporation, Redmond, WA, USA). The data are expressed as the mean \pm standard deviation, and then plotted using GraphPad Prism (version 6; GraphPad Software, Inc., La Jolla, CA, USA). The statistical differences among three or more groups were determined using analysis of variance followed by a Tukey's test. Student's t-test was used for comparisons between two groups. $\mathrm{P}<0.05$ was considered to indicate a statistically significant difference.

\section{Results}

H22 transplantation decreases BAT weight in mice. In order to investigate the association between HCC and BAT, the $\mathrm{H} 22$ mouse model was used to determine the effect of H22 transplantation on BAT. As presented in Table I, the weight of the liver in the $\mathrm{T}$ group was significantly greater compared with that of the $\mathrm{C}$ group $(\mathrm{P}<0.01)$. In addition, the weights of BAT and WAT for the T group were decreased compared with those of the $\mathrm{C}$ group; however, the difference was not statistically significant. As presented in Fig. 1A, the histopathological analysis of BAT, WAT and liver revealed no marked pathological changes prior to or following injection of $\mathrm{H} 22$ cells. The percentages of cross-sectional areas in BAT were 58.81 \pm 5.54 and 54.32 \pm 4.71 , respectively, for $\mathrm{C}$ and $\mathrm{T}$; and in WAT were $91.71 \pm 3.45$ and $90.52 \pm 4.25$, respectively, for $\mathrm{C}$ and $\mathrm{T}$. In order to analyze the biochemical serum indices of the two groups, the levels of CHO, HDL, LDL, TG and GLU were determined. The TG content in the serum of the T group increased significantly compared with that of healthy mice $(\mathrm{P}<0.01$; Table II).

Gene expression profiling analysis of the livers in the two groups of mice was also performed. Fig. 1B indicates that there was upregulation of genes involved in the cell cycle (including BUB1, CCNA2, CDC14A, CDK1, CDKN2C, E2F1, ESPL1 and GADD45B) and DNA replication-associated (including FEN1, MCM2, MCM3, MCM4, MCM5, MCM6, PCNA, POLA1, POLE, POLE2, PRIM1 and RNASEH2B) signaling pathways in the liver of the $\mathrm{T}$ group. In addition, a number of genes in metabolism-associated signaling pathways (including ACAA1B, ACSL1, AOX3, CYP1A2, ACAA1B, ACADSB, ACAA1B, ACACA, ACAA1B and ACOT1) were downregulated (Fig. 1C).

Removal of BAT in vivo promotes the growth of H22 tumors. Since H22 injection led to a decrease in the weight of BAT in mice, an in vivo BAT excision model was used to investigate the effect on H22 tumors of removing BAT. The tumor weight of the OT group was significantly larger $(\mathrm{P}<0.01)$ compared with that of the ST group, indicating that excision of BAT promoted the growth of $\mathrm{H} 22$ tumors (Table III). Compared with the $\mathrm{S}$ group, $\mathrm{H} 22$ injection led to a significant increase in liver weight in the ST group $(\mathrm{P}<0.05)$ and the removal of BAT also resulted in a significant increase in liver weight in the $\mathrm{O}$ group $(\mathrm{P}<0.05)$ (Table III). Furthermore, the liver weight in the OT group was higher compared with that of the O or ST group, but there was no significant difference in liver weight between the OT and $\mathrm{O}$ groups or between the OT and T groups. For the ST group, the weight of BAT and WAT decreased compared with 
Table III. Effect of BAT removal on body weight, tumor, liver, BAT and WAT in the BAT excision model.

\begin{tabular}{lccccc}
\hline Group & Body weight, $\mathrm{g}$ & Tumor, weight $\mathrm{g}$ & Liver weight, $\mathrm{g}$ & BAT weight, $\mathrm{g}$ & WAT weight, $\mathrm{g}$ \\
\hline S & $27.68 \pm 2.67$ & - & $1.764 \pm 0.381$ & $0.243 \pm 0.024$ & $0.142 \pm 0.028$ \\
ST & $28.87 \pm 2.73$ & $1.919 \pm 0.143$ & $2.128 \pm 0.198^{\mathrm{a}}$ & $0.223 \pm 0.042$ & $0.124 \pm 0.023$ \\
O & $29.28 \pm 1.51$ & - & $2.091 \pm 0.195^{\mathrm{a}}$ & - & $0.145 \pm 0.026$ \\
OT & $28.85 \pm 1.32$ & $2.802 \pm 0.468^{\mathrm{d}}$ & $2.322 \pm 0.280^{\mathrm{b}}$ & - & $0.106 \pm 0.015^{\mathrm{b}, \mathrm{c}}$
\end{tabular}

${ }^{\mathrm{a}} \mathrm{P}<0.05$ and ${ }^{\mathrm{b}} \mathrm{P}<0.01$ vs. $\mathrm{S} ;{ }^{\mathrm{c}} \mathrm{P}<0.01$ vs. $\mathrm{O}$; ${ }^{\mathrm{d}} \mathrm{P}<0.01$ vs. ST. BAT, brown adipose tissue; WAT, white adipose tissue; $\mathrm{S}$, sham; $\mathrm{ST}$, sham and tumor; $\mathrm{O}$, surgery; OT, surgery and tumor.
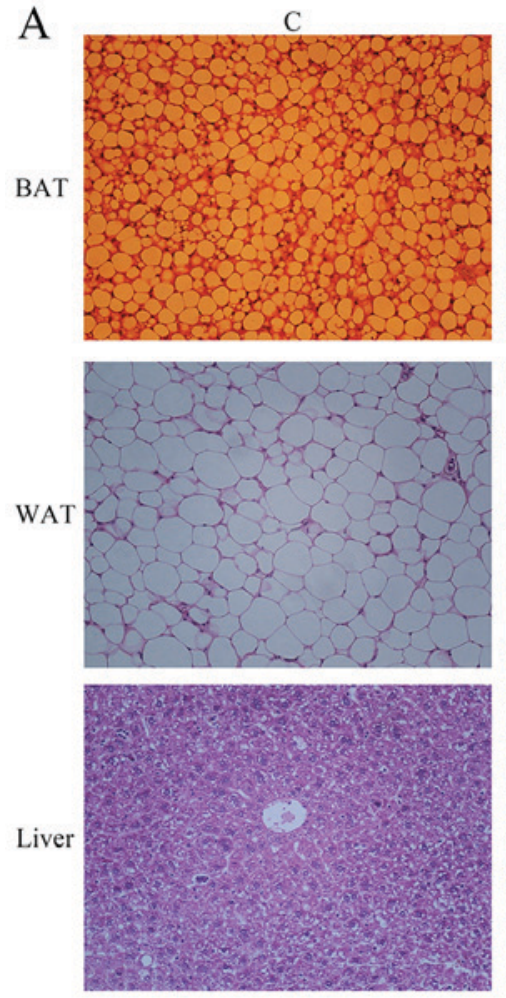
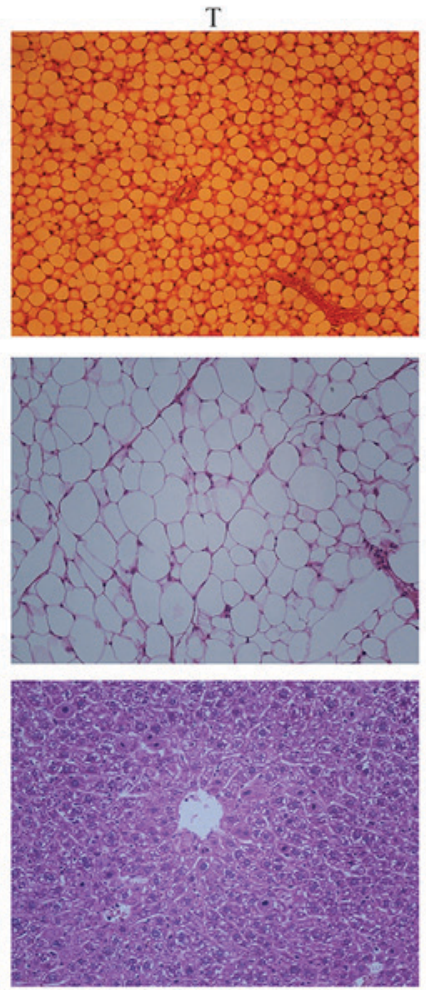

B

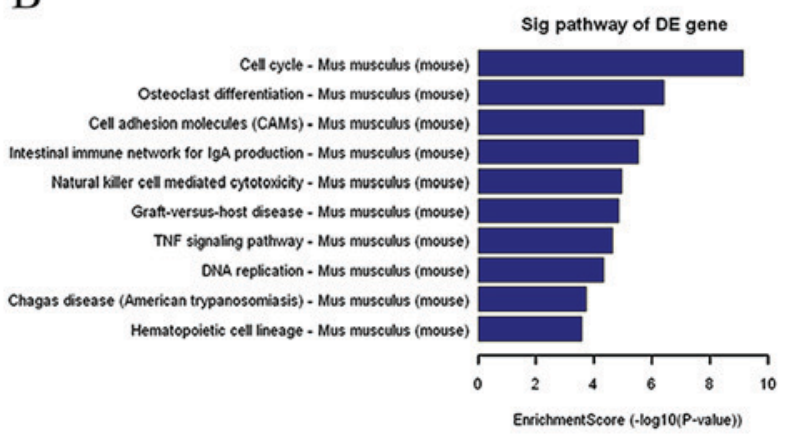

$\mathrm{C}$

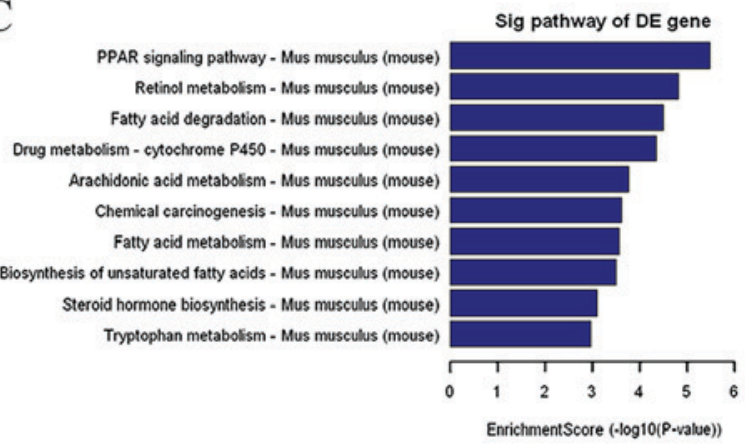

Figure 1. (A) H22 cell transplantation resulted in no pathological changes in BAT, WAT and liver in the C and T groups, as determined by hematoxylin and eosin staining (magnification, x200). The 10 most significantly (B) upregulated and (C) downregulated pathways in the liver for the group T vs. C as determined using Kyoto Encyclopedia of Genes and Genomes pathway analysis. BAT, brown adipose tissue; WAT, white adipose tissue; C, control; T, tumor; Sig, significant; DE, differentially expressed; IgA, immunoglobulin A; TNF, tumor necrosis factor; PPAR, peroxisome-proliferator-activated receptor.

in the $\mathrm{S}$ group where mice do not have tumors, but there was no significant difference between the two groups. The weight of WAT in the OT group was significantly less compared with in the $\mathrm{O}$ or $\mathrm{S}$ group $(\mathrm{P}<0.01)$. There were no marked pathological changes in sections of BAT, WAT and liver among different groups (Fig. 2). The percentages of cross-sectional areas in BAT were $57.20 \pm 4.96$ and $56.18 \pm 5.10$, respectively, for the S and ST groups; and in WAT were $94.13 \pm 2.94,93.04 \pm 2.13$, $92.07 \pm 2.43$ and $90.45 \pm 8.14$, respectively, for the S, ST, O and OT groups.

Since the functions of liver and BAT are associated with lipid metabolism, the serum concentrations of the biochemical indicators $\mathrm{CHO}, \mathrm{HDL}, \mathrm{LDL}, \mathrm{TG}$ and GL were determined (Table IV). For CHO, HDL, LDL and GLU, there was no significant difference in serum levels among the four groups. The patterns of changes in the serum level of TG among the four groups were similar with regard to liver weight. There was a significant increase in the serum level of TG in the ST or OT group compared with the $\mathrm{S}$ or $\mathrm{O}$ group, respectively $(\mathrm{P}<0.01)$. However, in contrast with the $\mathrm{S}$ group, the serum TG level in the $\mathrm{O}$ group increased slightly, but not significantly.

Primary BACs inhibit the viability of $\mathrm{H} 22$ cells and growth of tumors in vitro and in vivo. The aforementioned results indicated an interaction between H22 and BAT, so an intervention model with primary BACs was used to investigate the effect of BAT on the growth of $\mathrm{H} 22$ cells and tumors in vitro and in vivo. The mature BACs were stained with oil red $\mathrm{O}$ to validate the primary BACs (Fig. 3A).

As presented in Table $\mathrm{V}$, the growth of $\mathrm{H} 22$ tumors was markedly decreased owing to a mixture of BACs and $\mathrm{H} 22$ ascites in the inoculation suspensions. At the end of the 
Table IV. Effect of BAT removal on the serum concentration of CHO, HDL, LDL, TG and GLU in the BAT excision model.

\begin{tabular}{|c|c|c|c|c|c|}
\hline Group & $\mathrm{CHO}, \mathrm{mM}$ & HDL, mM & LDL, mM & $\mathrm{TG}, \mathrm{mM}$ & GLU, mM \\
\hline $\mathrm{S}$ & $2.19 \pm 0.47$ & $1.06 \pm 0.23$ & $0.26 \pm 0.07$ & $1.37 \pm 0.36$ & $5.04 \pm 1.00$ \\
\hline ST & $2.43 \pm 0.34$ & $0.94 \pm 0.09$ & $0.26 \pm 0.08$ & $2.37 \pm 0.94^{\mathrm{a}}$ & $5.04 \pm 0.94$ \\
\hline $\mathrm{O}$ & $2.28 \pm 0.30$ & $1.07 \pm 0.13$ & $0.21 \pm 0.09$ & $1.68 \pm 0.63$ & $5.08 \pm 0.90$ \\
\hline OT & $2.56 \pm 0.41$ & $1.08 \pm 0.19$ & $0.30 \pm 0.08$ & $3.09 \pm 1.06^{\mathrm{a}, \mathrm{b}}$ & $6.00 \pm 1.23$ \\
\hline
\end{tabular}

${ }^{\mathrm{a}} \mathrm{P}<0.01$ vs. S; ${ }^{b} \mathrm{P}<0.01$ vs. O. CHO, cholesterol; HDL, high-density lipoprotein; LDL, low-density lipoprotein; TG, triacylglycerol; GLU, glucose; S, sham; ST, sham and tumor; O, surgery; OT, surgery and tumor.

A
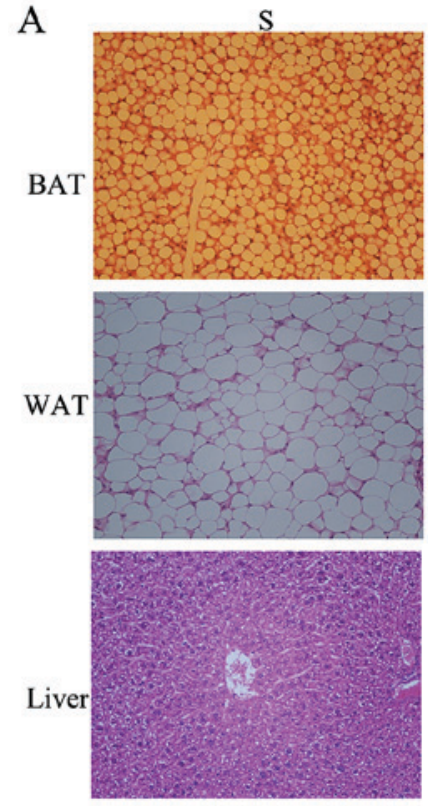
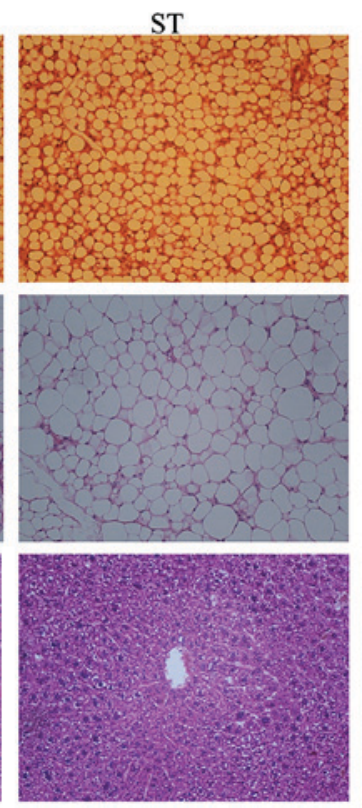

B
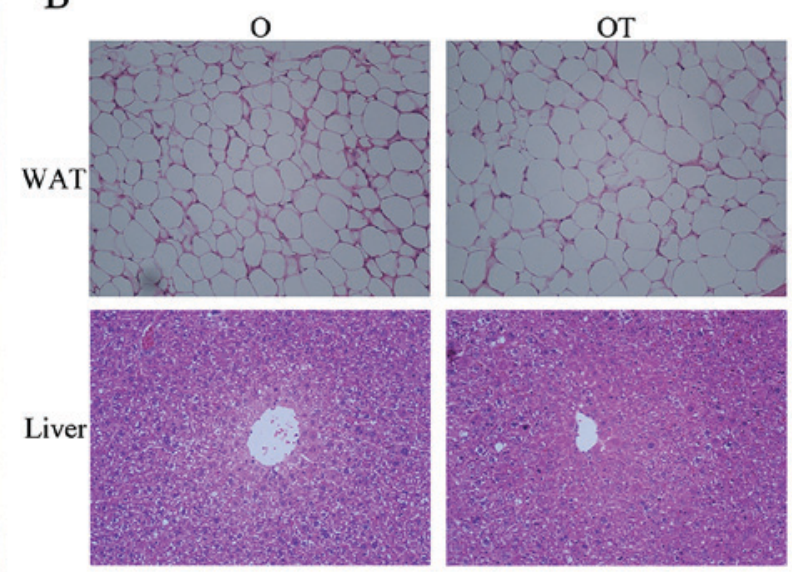

Figure 2. (A) In the in vivo BAT excision model, H22 cell transplantation leads resulted in no pathological changes in BAT, WAT and liver in the S and ST groups, as determined by H\&E staining (magnification, x200). (B) Removal of BAT and H22 transplantation resulted in no pathological changes in WAT and liver in the O or OT groups, as determined by H\&E staining (magnification, x200). BAT, brown adipose tissue; WAT, white adipose tissue; S, sham; ST, sham and tumor; O, surgery; OT, surgery and tumor; H\&E, hematoxylin and eosin.

experiment, the weight of the $\mathrm{H} 22$ tumor in the OT group reached $3.00 \pm 0.35 \mathrm{~g}$. When $7 \times 10^{5}$ and $14 \times 10^{5}$ BACs were mixed with the $\mathrm{H} 22$ inoculation suspensions, the final tumor weight decreased to $2.17 \pm 0.35$ and $1.72 \pm 0.46 \mathrm{~g}$, respectively. These changes were significant compared with the OT group with no BACs, which corresponded to inhibition rates of 27.67 and $42.67 \%$, respectively. However, injecting a mixture of BACs and H22 cells did not affect liver weight (Table V).

The results of the in vitro experiments are presented in Fig. 3B. The co-culture of the primary BACs and $\mathrm{H} 22$ cells was used to investigate the effect of BACs on the viability of $\mathrm{H} 22$ cells in vitro. The initial density of $\mathrm{H} 22$ cells was $2 \times 10^{5}$ cells $/ \mathrm{ml}$ in the lower compartment of the chamber, and, after $48 \mathrm{~h}$, the density of the $\mathrm{H} 22$ cells reached $1.65 \times 10^{6}$ cells $/ \mathrm{ml}$ in the blank control. Notably, when primary BACs were injected in the upper compartment of the chamber, the viability of the $\mathrm{H} 22$ cells was inhibited. The densities of the $\mathrm{H} 22$ cells were $134.08,109.08$ and $103.08 \times 10^{4}$ cells $/ \mathrm{ml}$ for $7.5 \times 10^{3}, 1.5 \times 10^{4}$ and $3 \times 10^{4}$ BACs, respectively, representing decreases in viability of $18.90,34.02$ and $37.65 \%$, respectively. Compared with the blank control, there was a significant difference in cell viability for $1.5 \times 10^{4}$ and $3 \times 10^{4}$ BACs $(\mathrm{P}<0.01)$.

KEGG analysis of the signaling pathways in the liver in $T$ and OT groups. From the aforementioned results, it was observed that BAT affected the growth of $\mathrm{H} 22$ tumors and, following H22 injection, the liver weight also changed. Therefore, the changes in hepatic signaling pathways following the resection of interscapular BAT and H22 injection were investigated. Tumor, liver and BAT weights in the five treatment groups (C, T, S, O and OT) were determined and analyzed. The pattern of the key indicators, including the weights of the association tissue in serum was similar to that of the aforementioned results. The weight of the liver in the T group was significantly greater compared with that of the $\mathrm{C}$ group. The tumor weight of the OT group was larger compared with that of the T group. The removal of BAT resulted in an increase in liver weight in the $\mathrm{O}$ group. Furthermore, the liver weight in the OT group was higher compared with that of the $\mathrm{O}$ or T group. The KEGG analysis of gene expression profiles of livers for the $\mathrm{T}$ and 
Table V. Body, liver and tumor weight, and tumor inhibition rate in the in vivo primary BACs intervention model.

\begin{tabular}{|c|c|c|c|c|}
\hline Group & Body weight, $g$ & Liver weight, $\mathrm{g}$ & Tumor weight, g & Inhibition rate, $\%$ \\
\hline OT (no BACs) & $30.74 \pm 3.25$ & $2.36 \pm 0.26$ & $3.00 \pm 0.35$ & - \\
\hline BACs1 $\left(7 \times 10^{5}\right.$ cells/mouse $)$ & $31.95 \pm 2.60$ & $2.54 \pm 0.29$ & $2.17 \pm 0.35^{\mathrm{a}}$ & 27.67 \\
\hline BACs $2\left(14 \times 10^{5}\right.$ cells/mouse $)$ & $30.92 \pm 2.79$ & $2.43 \pm 0.26$ & $1.72 \pm 0.46^{\mathrm{a}}$ & 42.67 \\
\hline
\end{tabular}

${ }^{\mathrm{a}} \mathrm{P}<0.01$ vs. OT (no BACs). BAC, brown adipose cell; OT, surgery and tumor.
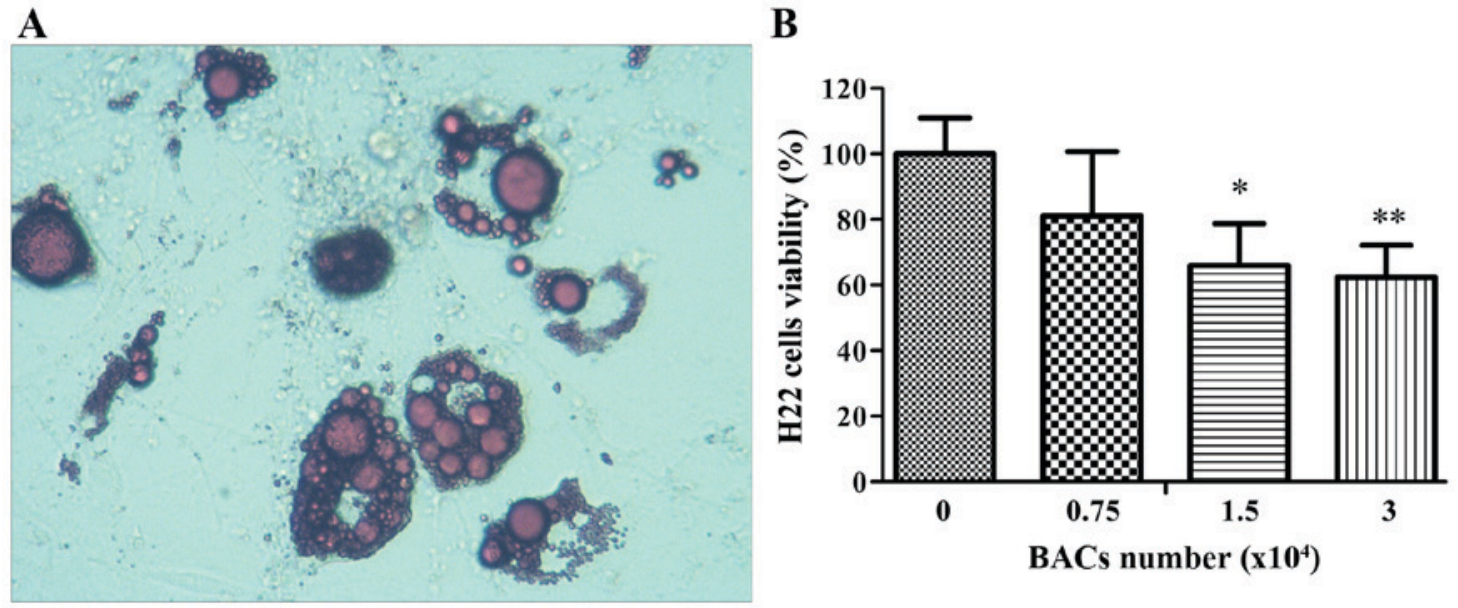

Figure 3. Primary BACs directly inhibit the viability of H22 cells. (A) Image of primary BACs stained with oil red O (magnification, x200). The interaction between $\mathrm{H} 22$ cells in the lower compartment and the BACs in the upper compartment after $48 \mathrm{~h}$ of co-culture was determined by counting the number of $\mathrm{H} 22$ cells with a blood counting chamber. (B) Results of the Transwell co-culture assay of the primary BACs and $\mathrm{H} 22$ cells to investigate the effect of BACs on the viability of $\mathrm{H} 22$ cells in vitro. ${ }^{*} \mathrm{P}<0.05$ and ${ }^{* *} \mathrm{P}<0.01$, vs. blank group with no BACs. BAC, brown adipose cells.
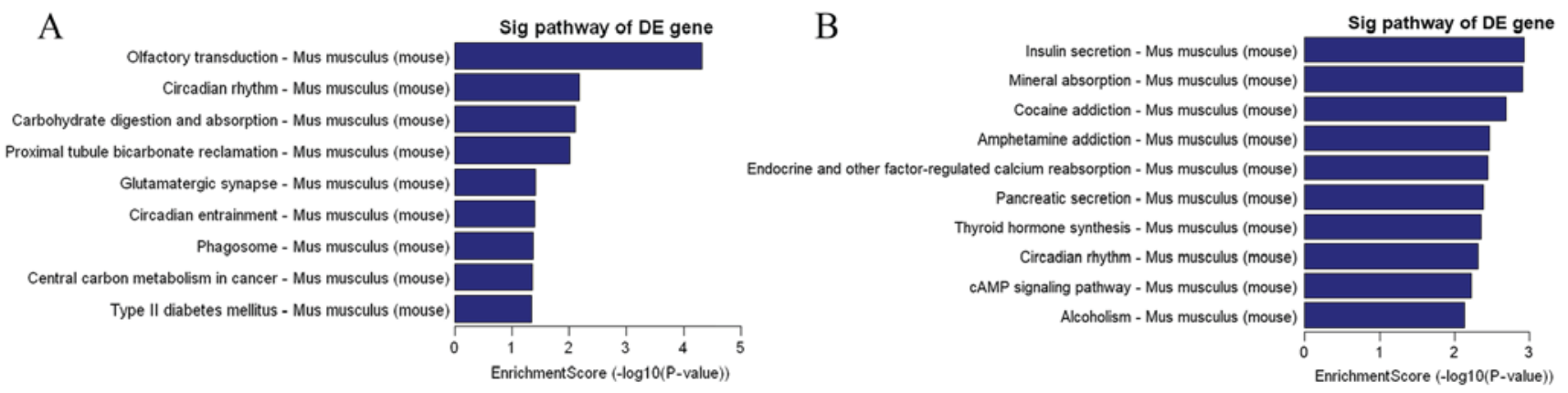

Figure 4. Results from Kyoto Encyclopedia of Genes and Genomes pathway analysis. The 10 most significantly (A) upregulated and (B) downregulated pathways in the liver for the group OT vs. T. OT, surgery and tumor; T, tumor; Sig, significant; DE, differentially expressed.

OT groups in presented in Fig. 4. Compared with the T group, the cancer-associated central carbon metabolism (including FGFR1, GLS, NTRK3, PDHA2, SIRT6 and SLC2A2) was enhanced in the OT group, which may be associated with tumor growth.

\section{Discussion}

Previous studies have identified that WAT is the major tissue associated with obesity (4), which is associated with an increased risk of HCC $(13,17)$, and BAT is an effective target for treating obesity (4). However, to the best of our knowledge, there has been no published study on the association between HCC and BAT.

The results of the present study indicate that BAT and BACs have an inhibitory effect on the viability of $\mathrm{H} 22$ cells and growth of tumors in vitro and in vivo. $\mathrm{H} 22$ transplantation led to increased liver weight, decreased BAT weight in the interscapular region and an increased serum level of TG in mice. The removal of BAT led to increased growth of $\mathrm{H} 22$ tumors, which was accompanied by a more marked increase in liver weight and serum level of TG. The primary BACs were able to inhibit the growth of $\mathrm{H} 22$ tumors in vivo. By removing BAT, the effect of inter-individual variation in the interscapular 
region was excluded, and the addition of BACs provided a more conducive environment for inhibiting the growth of H22 tumors. The primary BACs also directly limited the viability of H22 cells in the Transwell chamber for the co-culture assay.

At the beginning of the present study, the H22 mouse model was used to elucidate the association between HCC and metabolism. The H22 mouse model was characterized by an increase in liver weight, a decrease in the weight of BAT and WAT, and an increase in the serum TG level. The increased liver weight in the T group was consistent with the results of a previous study (18), which indicated that the injection of H22 cells markedly increased the liver indices. In this model, it was demonstrated that the serum TG content was increased following $\mathrm{H} 22$ transplantation, which could be associated with the downregulation of the fatty acid degradation signaling pathway.

The serum TG level is an important indicator for monitoring metabolic diseases. Non-alcoholic fatty liver disease is a common metabolic syndrome and may lead to the development of cirrhosis, which is a significant risk factor for HCC. Nderitu et al (19) identified that the increased TG level was associated with an increased risk of developing HCC. From pathological tissue biopsy results, the decrease in the weight of BAT and WAT without histopathological cell atrophy possibly arose from the decrease in the number of BACs or cellular contents. Therefore, the H22 mouse model indicated that HCC exerted a negative effect on BAT, which prompted the investigation of the role of BAT in HCC. Similar to the gene knockout method used for investigating gene function, BAT in the interscapular region was removed to observe the function of BAT in the growth of $\mathrm{H} 22$ tumors in the BAT excision model. The results indicated that the removal of BAT altered the liver weight and the serum TG level. Furthermore, the most marked changes in increased liver weight and serum TG content in the OT group were influenced by the removal of BAT and by H22 transplantation. Most notably, the growth of H22 tumors increased in the OT group compared with the ST group, which indicated that BAT could inhibit the growth of HCC.

The aforementioned results indicate an association between HCC and BAT, where HCC promotes the consumption of BAT and in turn BAT inhibits the growth of HCC. This suggests that BAT can secrete chemical substances or cytokines that inhibit the growth of HCC. Chen et al $(20,21)$ and Thomou et al (22) identified that exosomes secreted by BAT carried miRNAs that regulated other organs and tissues, such as the liver.

Owing to their accessibility, primary BACs were separated and used to interfere with the growth of $\mathrm{H} 22$ cells and tumors. The results from the in vitro and in vivo models support the hypothesis that BACs possess the potential to be an inhibitor of HCC. Coincidentally, in a study by Boyd et al (23) on the in vivo administration of peroxisome-proliferator-activated receptor $\gamma$ agonists to promote the proliferation of adipose cells in the bone marrow, acute myeloid leukemia cells were killed indirectly. Therefore, a treatment approach involving the culture of BACs on a large-scale and subsequent injection into patients with $\mathrm{HCC}$ was suggested.

It has been established that obesity is a risk factor for $\mathrm{HCC}$ and the browning of WAT is a possible strategy for treating obesity. The results of the present study demonstrated that BAT inhibits the growth of HCC, which further supports the hypothesis that exercise can decrease the risk of tumor. Overall, the association between HCC and BAT identified in the present study is of interest in the field of cancer and metabolism, and further investigation is required to define the roles of BAT in the growth of HCC. The unknown functions of BAT should be verified by more comprehensive experiments. The possibility of BACs as a therapeutic tool should be confirmed by further studies with HCC animal models.

\section{Acknowledgements}

Not applicable.

\section{Funding}

The present study was supported by the National Natural Science Foundation of China (grant no. 81621064) and CAMS Innovation Fund for Medical Sciences (CIFMS) (grant no. 2016-I2M-02-002).

\section{Availability of data and materials}

The datasets used and/or analyzed during the current study are available from the corresponding author on reasonable request.

\section{Authors' contributions}

SZC conceived the study and wrote the manuscript. DL, YL, YS, and WW conducted the animal experiments and YL prepared pathological section slices. DL conducted the other experiments. All authors read and approved the final manuscript.

\section{Ethics approval and consent to participate}

All animal experimental procedures were approved by the Beijing Municipal Science \& Technology Commission (Beijing, China) with the approval number of SYXK (Jing) 2017-0023.

\section{Patient consent for publication}

Not applicable.

\section{Competing interests}

The authors declare that they have no competing interests.

\section{References}

1. Bonnot E: The interscapular gland. J Anat Physiol 43: 43-58, 1908.

2. Truong MT, Erasmus JJ, Munden RF, Marom EM, Sabloff BS, Gladish GW, Podoloff DA and Macapinlac HA: Focal FDG uptake in mediastinal brown fat mimicking malignancy: A potential pitfall resolved on PET/CT. AJR Am J Roentgenol 183: 1127-1132, 2004

3. Nedergaard J, Bengtsson T and Cannon B: Unexpected evidence for active brown adipose tissue in adult humans. Am J Physiol Endocrinol Metab 293: E444-E452, 2007.

4. Virtanen KA, Lidell ME, Orava J, Heglind M, Westergren R, Niemi T, Taittonen M, Laine J, Savisto NJ, Enerbäck S and Nuutila P: Functional brown adipose tissue in healthy adults. N Engl J Med 360: 1518-1525, 2009. 
5. Cypess AM, Lehman S, Williams G, Tal I, Rodman D, Goldfine AB, Kuo FC, Palmer EL, Tseng YH, Doria A, et al: Identification and importance of brown adipose tissue in adult humans. N Engl J Med 360: 1509-1517, 2009.

6. van Marken Lichtenbelt WD, Vanhommerig JW, Smulders NM, Drossaerts JM, Kemerink GJ, Bouvy ND, Schrauwen P and Teule GJ: Cold-activated brown adipose tissue in healthy men. N Engl J Med 360: 1500-1508, 2009.

7. Wu J, Boström P, Sparks LM, Ye L, Choi JH, Giang AH, Khandekar M, Virtanen KA, Nuutila P, Schaart G, et al: Beige adipocytes are a distinct type of thermogenic fat cell in mouse and human. Cell 150: 366-376, 2012.

8. Sprinzl MF and Galle PR: Current progress in immunotherapy of hepatocellular carcinoma. J Hepatol 66: 482-484, 2017.

9. Kudo M, Han G, Finn RS, Poon RT, Blanc JF, Yan L, Yang J, Lu L, Tak WY, Yu X, et al: Brivanib as adjuvant therapy to transarterial chemoembolization in patients with hepatocellular carcinoma: A randomized phase III trial. Hepatology 60: 1697-1707, 2014

10. Chuah B, Lim R, Boyer M, Ong AB, Wong SW, Kong HL Millward M, Clarke S and Goh BC: Multi-centre phase II trial of thalidomide in the treatment of unresectable hepatocellular carcinoma. Acta Oncol 46: 234-238, 2007.

11. Cainap C, Qin S, Huang WT, Chung IJ, Pan H, Cheng Y, Kudo M, Kang YK, Chen PJ, Toh HC, et al: Linifanib versus Sorafenib in patients with advanced hepatocellular carcinoma: Results of a randomized phase III trial. J Clin Oncol 33: 172-179, 2015.

12. Rahib L, Smith BD, Aizenberg R, Rosenzweig AB, Fleshman JM and Matrisian LM: Projecting cancer incidence and deaths to 2030: The unexpected burden of thyroid, liver, and pancreas cancers in the United States. Cancer Res 74: 2913-2921, 2014.

13. Agosti $\mathrm{P}$, Sabbà $\mathrm{C}$ and Mazzocca $\mathrm{A}$ : Emerging metabolic risk factors in hepatocellular carcinoma and their influence on the liver microenvironment. Biochim Biophys Acta Mol Basis Dis 1864: 607-617, 2018.

14. Vargas-Castillo A, Fuentes-Romero R, Rodriguez-Lopez LA, Torres $\mathrm{N}$ and Tovar AR: Understanding the biology of thermogenic fat: Is browning a new approach to the treatment of obesity? Arch Med Res 48: 401-413, 2017.
15. Marko O, Cascieri MA, Ayad N, Strader CD and Candelore MR: Isolation of a preadipocyte cell line from rat bone marrow and differentiation to adipocytes. Endocrinology 136: 4582-4588, 1995.

16. Gao W, Kong X and Yang Q: Isolation, primary culture, and differentiation of preadipocytes from mouse brown adipose tissue. Methods Mol Biol 1566: 3-8, 2017.

17. Karagozian R, Derdák Z and Baffy G: Obesity-associated mechanisms of hepatocarcinogenesis. Metabolism 63: 607-617, 2014.

18. Shi WR, Liu Y, Wang XT, Huang QY, Cai XR and Wu SR Antitumor efficacy and mechanism in hepatoma H22-bearing mice of brucea javanica oil. Evid Based Complement Alternat Med 2015: 217494, 2015.

19. Nderitu P, Bosco C, Garmo H, Holmberg L, Malmström H, Hammar N, Walldius G, Jungner I, Ross P and Van Hemelrijck M: The association between individual metabolic syndrome components, primary liver cancer and cirrhosis: A study in the Swedish AMORIS cohort. Int J Cancer 141: 1148-1160, 2017.

20. Chen Y, Buyel JJ, Hanssen MJ, Siegel F, Pan R, Naumann J, Schell M, van der Lans A, Schlein C, Froehlich $\mathrm{H}$, et al: Exosomal microRNA miR-92a concentration in serum reflects human brown fat activity. Nat Commun 7: 11420, 2016.

21. Chen Y and Pfeifer A: Brown fat-derived exosomes: Small vesicles with big impact. Cell Metab 25: 759-760, 2017.

22. Thomou T, Mori MA, Dreyfuss JM, Konishi M, Sakaguchi M, Wolfrum C, Rao TN, Winnay JN, Garcia-Martin R, Grinspoon SK, et al: Adipose-derived circulating miRNAs regulate gene expression in other tissues. Nature 542: 450-455, 2017.

23. Boyd AL, Reid JC, Salci KR, Aslostovar L, Benoit YD, Shapovalova Z, Nakanishi M, Porras DP, Almakadi M, Campbell CJV, et al: Acute myeloid leukaemia disrupts endogenous myelo-erythropoiesis by compromising the adipocyte bone marrow niche. Nat Cell Biol 19: 1336-1347, 2017.

This work is licensed under a Creative Commons Attribution-NonCommercial-NoDerivatives 4.0 International (CC BY-NC-ND 4.0) License. 